\title{
p53-protein over-expression and gene mutational of oral carcinoma in-situ
}

\author{
Mei Syafriadi* and Takashi Saku** \\ ${ }^{*}$ Division of Pathology, Department of Biomedical Sciences, Faculty of Dentistry, Jember University \\ ** Division of Oral Pathology, Department Oral Life Sciences, Graduates School of Medical and Dental Sciences, Niigata University, Japan
}

\begin{abstract}
We had been reported histological types of oral carcinoma in-situ (oral CIS), such as basaloid, verrucous, and acanthothic/ atrophic types. We considered that they have different histological appearance influenced by molecular behavior. To understand the molecular behavior of them we examined p53 exon 4-8 gene mutation and their protein expression. Using 35 cases formalin-fixed paraffin sections of oral CIS and 10 cases of mild and moderate squamous epithelial displasia (SED) as a control were subjected to p53 immunohistochemistry. In the next step all cases were subjected to p53 gene mutations analysis by laser capturing microdissection and direct sequencing of PCR product for exon 4-8. Showed that p53-protein over-expression were found in basal layer of SED and the p53 protein over-expression were confined in the whole layer of CIS-basaloid type, basal and parabasal layers of CIS-verrucous type, and sporadically in the basal layer of CIS-acanthothic type. Mutational analysis for p53 gene showed $43 \%$ of total cases of CIS had 553 gene mutation therefore CIS-basaloid type had mutations more frequently than the other types and mutation in exon 8 more dominant than other exons, which had some common mutation at codons 196, 248, 282, 291, and 306, while no particular mutations were found in control (SED). Our criteria to diagnose several types of oral carcinoma in-situ by p53 protein expression and mutational analysis could be used to understand molecular behavior of CIS.
\end{abstract}

Key words: p53, carcinoma in-situ, oral, mutation

Correspondence: Mei Syafriadi, c/o: Laboratorium Patologi, Bagian Biomedik, Fakultas Kedokteran Gigi Universitas Jember. Jl. Kalimantan 37 Jember 68121, Indonesia. E-mail: mei_syafriadi@ hotmail.com

\section{INTRODUCTION}

It is known that carcinoma in-situ (CIS) composed of dysplastic change of squamous epithelium does not have keratinization, but it is different to dysplastic change arising in the oral cavity, which has prominent keratinization. ${ }^{1}$ According to carcinoma which arise only limited in intra epithelial, many authors using different term such as severe dysplasia, ${ }^{2}$ or squamous intra neoplasia (SIN) high grade. ${ }^{3}$ Whereas WHO classified oral CIS as one classification that separate to squamous epithelial dysplasia (SED) classification. $^{4}$

The concept of oral CIS is the most important aspect in the present criteria, because SED and invasive squamous cell carcinoma (SCC) can be easily discriminated however when and what stage could be called as CIS is still unclear and controversial because there has not any fixed criteria yet.

CIS has defined as a true and not invasive neoplasm yet lying within an epithelial layer. The neoplastic cells are different from SED, because they have already been proliferated and subsequently differentiated. In epithelial dysplasia, the constituent cells are only proliferated but not differentiated yet. ${ }^{5}$

As we reported before, we have noticed that oral CIS histologically has any mimicking which classified to CISbasaloid type, CIS-verrucous type and CIS-acanthotic type ${ }^{6}$ which all of them are not invasive yet. ${ }^{7}$ Based on this histological appearance, we speculated that those CIS types are several molecular behaviors.

The p53 gene structure is consist of eleven exon which is exon $2-3$ is transactivation domain, exon $5-8$ is DNA binding domain and exon 10 is oligomerization domain that they have multifunctional such as transcription factor, which regulates cell cycle progression and interacts with several key proteins which involved in DNA replication, transcription and reparation.

Nearly $60 \%$ of human cancers are accompanied by mutation in p53 gene. ${ }^{8}$ The p53 protein over-expression is frequently found in both malignant and dysplastic lesions which increase due to grades of dysplasia, and may be an early event in multistage carcinogenesis of head and neck cancer. ${ }^{8-13}$ The abnormal p53 protein expression reported in 10 to $80 \%$ of oral SED, ${ }^{14-19}$ that some cases related to p53 gene mutation. ${ }^{8,9,19,20}$ However, in some cases it was possible to observe protein over expression but did not show any mutation gene or p53 gene mutation without P53 protein expression ${ }^{20}$ but Chiang et al. ${ }^{21}$ reported p53 over expression were correlated to decreasing of survival rate of patient with squamous cell carcinoma.

Based on it we observed p53 gene exon 4-8 and its protein expression in several types of oral CIS. The purpose is to understand their molecular behavior chances by protein expression pattern and gene mutation. 


\section{MATERIALS AND METHODS}

Specimen were formalin paraffin-fixed block selected from the surgical pathology files in the Division of Oral Pathology, Niigata University Graduate School of Medical and Dental Sciences, Japan, during sixth year period from 1999 to 2004 and eleven biopsy specimens from Department of Oral Pathology, Sichuan University School of Stomatology, China, during 2000-2002, after critical reviewing of hematoxylin and eosin (HE) stained sections. These researches consisted of ten cases of oral SED (mild and moderate cases) as a control and 35 of CIS (15 cases basaloid, 10 cases verrucous and 10 cases acanthothic type). Two oral pathologists with the Japanese Society of Pathology board certification and one pathologist from China screened all the specimens, when the diagnoses of grading of CIS were not identical those cases would be reevaluated together. All of the specimens were routinely fixed in $10 \%$ formalin and embedded in paraffin. Serial 4 $\mu \mathrm{m}$ sections were cut from paraffin blocks. One set of the sections was stained with hematoxylin and eosin and used for reevaluation of histological diagnosis, and the other sets were toluidine blue staining used for microdissection as well as immunohistochemistry for p53 protein.

The antibodies against p53-protein used in this study were mouse monoclonal antibody clone Bp53-11, $\left(\operatorname{IgG}_{2 \mathrm{a}}\right)$ (Progen, Progen Biotechnik GmbH, Heidelberg, Germany), that reacted to wild-type and mutant forms of human p53 antigen within N-terminal region epitope aa20-31. For immunohistochemistry staining were tissue sections $4 \mu \mathrm{m}$ in thickness were taken from tissue blocks. After deparaffinization and dehydration, sections were washed in $0.01 \mathrm{M}$ phosphate buffered saline (PBS). To restore the antigenic sites, sections were autoclaved in $0.01 \mathrm{M}$ citrate buffer ( $\mathrm{pH} \mathrm{6.0)}$ ) for $15 \mathrm{~min}$ at $121^{\circ} \mathrm{C}$ and then kept standing for $20 \mathrm{~min}$ at room temperature. To block endogenous peroxidase activities, all the sections were quenched with $0.001 \% \mathrm{H}_{2} \mathrm{O}_{2}$ in $100 \%$ methanol for 30 min at room temperature and rinsed with PBS containing $0.5 \%$ skim milk and $0.05 \%$ triton X-100 (PBST). After rinsing in PBST, the sections were incubated in 5\% skim milk in PBS containing $0.05 \%$ TritonX-100 for $1 \mathrm{hr}$ at $37^{\circ} \mathrm{C}$ to block non-specific protein bindings. The sections were then incubated with monoclonal primary antibodies against p53-protein were p53-protein/clone p53 AbBp53-11 (1: 100, Progen Biotechnik GMBH, Heidelberg, Germany), for overnight at $4^{\circ} \mathrm{C}$. After incubations with the primary antibodies, the sections were rinsed in PBST and then treated with polymer-immune complexes (Envision+peroxides, rabbit/mouse, Dako, 1:1) for $1 \mathrm{hr}$ at room temperature. The peroxidase reaction products were visualized by incubation with $0.02 \% 3$, 3-diaminobenzidine (DAB, Dohjin Laboratories, Kumamoto, Japan) in $0.05 \mathrm{M}$ Tris- $\mathrm{HCl}$ solution ( $\mathrm{pH} 7.6$ ) containing $0.005 \% \mathrm{H}_{2} \mathrm{O}_{2}$. The sections were counterstained with hematoxylin. Cells were regarded as positive for p53 protein if nuclear staining was intense and could be readily visualized at 10 times magnification. Positive staining for p53 protein staining were calculated quantitatively using a micrometer scale $1 \mathrm{~mm} /$ square at 10 times magnification. Calculation of positive cells had been done three times and the average was taken. For control experiments, the primary antibodies were replaced with pre-immune mouse IgG2a (Dako).

After evaluation of immunostaining pattern for $\mathrm{p} 53$, each sample was stained by toluidine blue for laser microdissection (LMD). Appropriate ten of slides each case were cutted due to appropriate area and collected in collection tube for extracted DNA using Proteinase K 10\% for one night at $37^{\circ} \mathrm{C}$. The DNA solution was purified using phenol/chloroform/isoamyl alcohol mixture (25:24:1). PCR amplification was carried out for p53 exons 4-8. All primer sets were designed on intron sequences adjacent to each exon as follow: [exon 4] sense, 5'-TGC TCT TTT CAC CCA TCT AC-3', antisense, 5'-ATA CGG CCA GGC ATT GAA GT-3' spanning 353 bps; [exon 5] sense, 5'-GTT TCT TTG CTG CCG TGT TC-3', antisense, 5'-AGG CCT GGG GAC CCT GGG CA-3' spanning 323 bps; [exon 6] sense, 5'-TGG TTG CCC AGG GTC CCC AG-3', antisense 5'-GGA GGG CCA CTG ACA ACC A-3' spanning 223 bps; [exon 7] sense, 5'-CTT GCC ACA GGT CTC CCC AA-3', antisense 5'-TGT GCA GGG TGG CAA GTG GC3' spanning 196 bps; [exon 8] sense, 5'-TTC CTT ACT GCC TCT TGC TT-3', antisense 5' - CGC TTC TTG TCC TGC TTG CT-3' spanning 201 bps. PCR were performed on a thermal cycler (PC-800, Astec Co., Ltd., Fukuoka Japan), after a pre-denaturation at $94^{\circ} \mathrm{C}$ for 5 minutes. The amplification step was carried out for 35 cycles in $100 \mu \mathrm{l}$ of a PCR reaction mixture containing 5 units of TaKaRa Ex taq polymerase (Takara Biotechnology, Co., Ltd., Otsu, Japan), 10× Ex Taq buffer, $2.5 \mathrm{mM}$ each of dNTP mixtures, and 20 pmol of each sense and antisense primers. The thermal cycling condition was as follow: denaturation at $94^{\circ} \mathrm{C}$ for $1 \mathrm{~min}$, annealing at $63^{\circ} \mathrm{C}$ for exon 5 , at $60^{\circ} \mathrm{C}$ for exon 4,6 , and 8 , and $62^{\circ} \mathrm{C}$ for exon 7 for $0.30 \mathrm{sec}$ each, and extension at $72^{\circ} \mathrm{C}$ for $1 \mathrm{~min}$. The last extension was prolonged by additional $7 \mathrm{~min}$. Amplification products were analyzed by electrophoresis on 3\% agarose gel (NuSieve 3:1 agarose, Cambrex BioScience Rockland Inc., Rockland, ME USA) and the band were visualized by ethidium bromide upon exposure to an ultraviolet transilluminator.

All PCR products were subjected to cycle sequencing by using Thermo Sequenase Primer Cycle Sequencing Kit with 7-deaza -dGTP (Amersham Biosciences Corp., Piscataway, USA). The sequence primers were synthesized based on the published data (Lehman TA et al.) and labeled with Texas red 5'-end. The labeled primers were as follow: 5'- TGC TCT TTT CAC CCA TCT AC-3' for exon 4; 5'-GTT TCT TTG CTG CCG TGT TC-3' for exon 5; 5'-GCC TCT GAT TCC TCA CTG AT-3' for exon 6; 5'-CTT GCC ACA GGT CTC CCC AA-3' for exon 7; 5'-TTC CTT ACT GCC TCT TGC TT-3' for exon 8. One tube sequencing reaction contained $3 \mu \mathrm{l}$ of master mixes (appropriate nucleotides/ reaction buffer/thermo sequenase DNA polymerase), $2 \mu \mathrm{l}$ of the template PCR products, which were purified with 
GFX PCR DNA and gel band purification kits (Amersham Biosciences Corp., Piscataway, USA), $8 \mu \mathrm{l}$ of distillated water and $2 \mu \mathrm{l}(2 \mathrm{pM})$ of Texas red-labeled primers. Each sequencing reaction added $3 \mu \mathrm{l}$ of $\mathrm{A}, \mathrm{C}, \mathrm{G}, \mathrm{T}$ reagent. After denaturation at $95{ }^{\circ} \mathrm{C}$ for $30 \mathrm{sec}$ and annealing at $55{ }^{\circ} \mathrm{C}$ for $30 \mathrm{sec}$. the reaction products were dissolved in $3 \mu 1$ loading dye by vortexing and concentrated with vacuum desiccators. Then $3 \mu \mathrm{l}$ of samples for each lane were loaded on a gel (7\% Long Ranger/6.1 M urea/1.2 $\times$ TBE buffer (10 mM Tris, $10 \mathrm{mM}$ boric acid, and $2 \mathrm{mM}$ EDTA). The electrophoresis was performed in a fluorescent DNA sequencer (SQ-5500-S, Hitachi Ltd., Tokyo, Japan), and the sequencing data were analyzed by using the SQ-5500 analysis software ver.3.03 (Hitachi).

For statistical analysis, the numbers of p53 and Ki-67 positive cells in a square unit $1 \mathrm{~mm}^{2}$ were counted on a microscope equipped with a micrometer. Ten fields were randomly counted per section at $\times 100$ magnification. OneWay ANOVA was used for statistical comparison of cell numbers between each group by using the SPSS software program (SPSS Inc., Chicago, IL, USA).

\section{RESULT}

Oral SED-mild is regarded to lesions with low proliferation and considered as low risk malignant transformation, but it could continue proliferate to moderate dysplasia and CIS which classified to basaloid, acanthotic and verrucous type. In oral CIS-basaloid there is basaloid cells proliferation that replaces whole layer of epithelium, but it still shows differentiation and keratinization in the surface layer. The verrucous type is characterized by round shape of rete processes, gradual differentiation, and enhanced keratinization in the surface. The keratinization creates keratin plugs formation. The acanthothic type is the most difficult subtype to be diagnosed, because it looks like SED due to cells proliferation and fairly extent of keratinocytic differentiation. Although this type has distinctive keratinization often on the surface, their rete processus are sharp, finger looks and tends to infiltrate to lamina propria (Figure 1).

Immunohistochemical staining for p53 protein, when observed, was found exclusively in the nuclei of epithelial cells. In SED-mild, p53-protein was over-expressed in basal and parabasal layer (Figure 2-A), in basaloid type it was expressed in whole layer (Figure 2-B), sporadically until one-third of epithelium of CIS-acanthothic (Figure 2-C), and over-expressed in two-third of epithelium in verrucous type. In some cases, both in basaloid types or verrucous types showed no p53 protein expression (Figure 2-D). When dysplastic cells were transformed to CISacanthothic, basaloid and verrucous type, it increased of p53-protein expression in number statistically significant $(\mathrm{p}<0.05)$ (Figure 3).

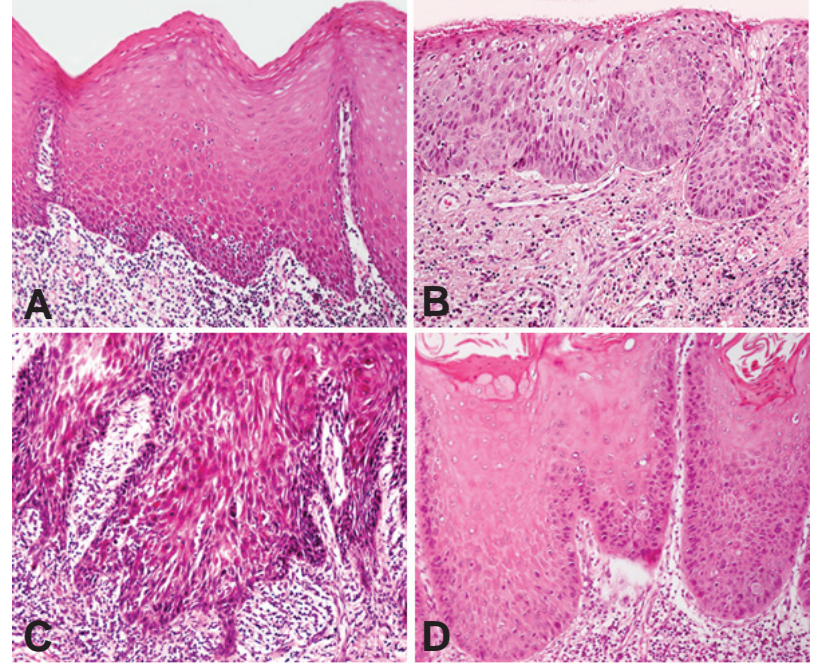

Figure 1. Histological appearance of several types of oral CIS (A), SED-mild (B), CIS-basaloid type (C), CISacanthothic type (D), CIS-verrucous type.

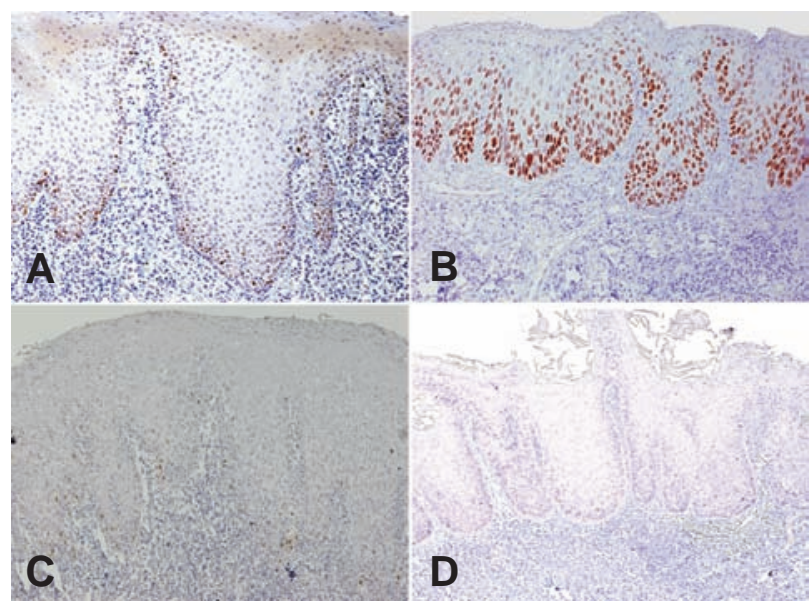

Figure 2. Immunostaining of p53 protein over expressed in SED-mild (A), CIS-basaloid (B), CIS-acanthothic type (C), and CIS-verrucous type. In some cases either basaloid type or verrucous type showed no $\mathrm{p} 53$ protein expression (D).

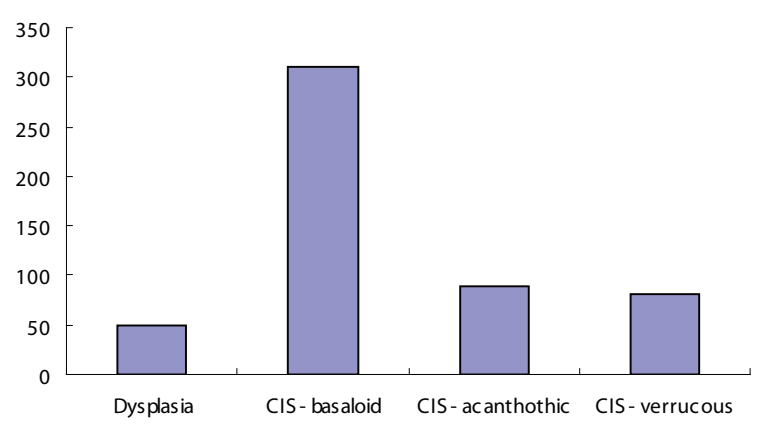

Figure 3. p53-protein expression was increased significantly from SED to CIS-basaloid, acanthothic and verrucous type. 
Table 1. p53 gene mutational analysis in SED and CISs

\begin{tabular}{cccccc}
\hline No. & Cases & p53 gene mutation & No. & Cases & p53 gene mutation \\
\hline 1 & SED-mild & - & 14 & CIS-basaloid & E8: 263, AAT-AAG \\
& & & & & 282,CGG-TGG \\
2 & SED moderate & - & 15 & CIS-basaloid & - \\
3 & SED-mild & - & 1 & CIS-acanthothic & - \\
4 & SED-moderate & - & 2 & CIS-acanthothic & - \\
5 & SED-mild & - & 3 & CIS-acanthothic & - \\
6 & SED-moderate & - & 4 & CIS-acanthothic & - \\
7 & SED-moderate & - & 5 & CIS-acanthothic & E8:282, CGG-TGG \\
8 & SED-moderate & - & 6 & CIS-acanthothic & E7:243, ATG-AAG \\
9 & SED-moderate & - & 7 & CIS-acanthothic & E7:231, ACC-GCC \\
10 & SED-mild & - & 8 & CIS-acanthothic & E8:263, AAT-AAG \\
1 & CIS-basaloid & E8:282, CGG-TGG & 9 & CIS-acanthothic & - \\
2 & CIS-basaloid & E7:248,CGG-CAG & 10 & CIS-acanthothic & - \\
3 & CIS-basaloid & E6:196, CGA-TGA & 1 & CIS-verrucous & - \\
4 & CIS-basaloid & - & 2 & CIS-verrucous & - \\
5 & CIS-basaloid & E8:276, GCC-ACC & 3 & CIS-verrucous & - \\
6 & CIS-basaloid & E7:237, ATG-ATA & 4 & CIS-verrucous & - \\
7 & CIS-basaloid & E8:306, CGA-TGA & 5 & CIS-verrucous & - \\
8 & CIS-basaloid & - & 6 & CIS-verrucous & E8:306, CGA-TGA \\
9 & CIS-basaloid & - & 7 & CIS-verrucous & - \\
10 & CIS-basaloid & E8:282, CGG-TGG & 8 & CIS-verrucous & E7:242, TGC-TTC \\
11 & CIS-basaloid & - & 9 & CIS-verrucous & - \\
12 & CIS-basaloid & E8:291, AAG-TAG & 10 & CIS-verrucous & - \\
13 & CIS-basaloid & - & & & \\
\hline & & & & &
\end{tabular}

All of dysplasia cases and CIS were sequencing for p53 gene analyses of exon 4-8. 40\% of CIS-acanthothic; $20 \%$ of CIS-verrucous, $60 \%$ of CIS-basaloid, had shown p53 gene mutation. Therefore, exon 4 had not showed any mutation but several cases showed pleomorphism in codon 72. All of $\mathrm{p} 53$ gene mutation in CISs were point mutations (100\%) of which result were $66 \%$ missense, and nonsense were $33 \%$. meanwhile no mutation were found in dysplasia cases (Table 1).

\section{DISCUSSION}

Oral CIS histologically showed irregular stratification, lost of epithelial cell cohesion, increasing of N/C ratio hyperchromatic, nuclear polymorphism, and preserved basement membrane. ${ }^{4,5}$ The surface layer covered by keratin and hyperparakeratin layer, therefore, clinically showed white lesion. Some parts of this histological appearance were similar to dysplastic change of SED, but CIS showed more dysplastic changed than SED and not invasive yet which we considered to be an advanced stage of moderate dysplasia (Figure 1). According to WHO, squamous epithelial dysplasia showed 13 representative appearances and classified to SED-mild, moderate and severe dysplasia, however, the borderline between mild, moderate, and severe dysplasia was not clear. ${ }^{4}$ Meanwhile many pathologists called severe dysplasia as CIS.

Recently we introduced several histological subtypes of oral CIS such as CIS-basaloid, verrucous and acanthotic type. ${ }^{6}$ The verrucous type was characterized by round shape of rete processes, gradual differentiation, and enhanced keratinization in the surface. The keratinization created keratin plugs formation. The acanthotic type was the most difficult subtype to be diagnosed, because it looked like SED due to cells proliferation and fairly extent of keratinocytic differentiation. Although this type often has distinctive keratinization often on the surface, their rete processus were sharp, finger looked and tended to infiltrate to lamina propria (Figure 1-C).

All of CIS subtypes showed preservation of basement membrane and no stromal induction, but it should get more intention for clinician because not only oral CIS different from CIS cervix uteri but also they were potential transform to SCC which showed destruction of basement membrane and some small carcinomatous foci formation that could invade close to muscle layer and also followed by stromal formation.

The present study demonstrated distinction of localization and number of positive cells of p53-protein over-expression 
of CIS-acanthothic, verrucous, and basaloid type and SED. The location of p53-protein expression started from basal layer of SED-mild then involving parabasal cells due to severity of dysplasia, ${ }^{11,17}$ in this study it was highly overexpressed in whole layer of CIS-basaloid type (Figure 3). Cruz et al. ${ }^{17}$ reported that p53 protein expression above basal cell layer is as early even of malignant transformation, but why their over-expression pattern different in those CIS subtypes and SED were not documented yet.

The over-expression of protein 53 started from basal layer of SED-mild and then involved two or three parabasaloid layer of SED-moderate, and their expression more enhanced in CIS-verrucous which was expressed whole of basaloid cells but not in middle layer because of keratinization there were present seemed-like keratin plug. It means that type some cells are showed differentiation, contrast to CIS-basaloid type which basaloid cells replaced whole layer and all basaloid cells showed p53 protein over-expression, meanwhile, p53 protein over-expression in CIS-acanthothic type were sporadic which seemed the same to moderate dysplasia (Figure 2).

p53 protein over-expression in head and neck carcinoma were related to gene mutation or none, ${ }^{8,9,19,20}$ similar with this present study, those CIS-verrucous, acanthothic, and basaloid, showed p53 protein over-expression but only $43 \%$ of CIS cases found any p53 mutation, $57 \%$ of cases found no p53 gene mutation. In SED some cells showed p53 protein expression but had not shown any mutation. Several cases showed no p53 protein immunopositivities, because p53 gene mutation had stop codons mutation, and the antibody could not detect $\mathrm{p} 53$ protein expression because protein had not been produced yet.

CIS-basaloid showed more dominantly p53 gene mutation than other types which, histologically, increased basaloid cell proliferation and decreased keratinization. CIS-basaloid type could be considered as malignant transformation, meanwhile, CIS-verrucous and acanthothic type, even though it showed few p53 gene mutations but it should also be considered as high risk malignant transformation because several cases found p53 gene mutation. Involving other onco-supressor gene should be thought as possible factor to p53-protein over-expression even no p53 gene mutation in SED and CIS, because it is known that $\mathrm{p} 53$ gene produce protein interacts to other gene such as p21 and p63 or p73. ${ }^{8}$

p53 gene mutation in CIS occurred in varies exon but exon 8 more frequently (53\% of total mutation cases) and was followed by exon 7 (40\% of total mutation cases) and codon 248, 282 in exon 7 and 8 known as "hot spot". In addition, other point mutation in exon 6 and exon 8 codon 196 (CGA $\rightarrow$ TGA) resulted from arginine to stop codon; codon 291 (AAG TAG) resulted from lysine to stop codon and codon $306(\mathrm{CGA} \rightarrow \mathrm{TGA})$ resulted from Arginine to stop codon also found. These mutations were denoted as hot spots of p53 mutations. Several study showed that arginine residue function is involving in DNA repair, ${ }^{22}$ so if there is mutation in this protein it could consider that DNA failed to repair their DNA damage.

Many reports demonstrated p53 gene mutation of head and neck carcinoma and showed similarity to CIS p53 gene mutation in this present study, it suggested oral squamous cell carcinoma was starting from carcinoma in-situ but it needed more study to understand the malignancy occurring in head and neck cancer or in oral carcinoma.

From this research could be concluded that histologically oral CIS has three subtypes such as CIS-basaloid, verrucous and acanthothic/atrophic type. The differences of those types not only in histological appearance but also it showed different p53 protein over-expression pattern. p53 gene mutation analysis showed CIS-basaloid type that frequently had point mutation than other types. It considered that CIS-basaloid type is potentially transform to SCC because of some mutation was involving hot spot of p53 gene mutation as reported in head and neck carcinoma. p53 gene mutation in CIS had stop codon mutation, showing no protein immunopositivities could be detected by antibody against p53 protein. p53 protein over-expression could be detected in basal and parabasal of SED but no p53 gene exon 4-8 mutations were found. From this present study it could suggested that oral CIS subtypes could be clearly distinguished from their subtypes and SED by p53 protein expression and mutational gene analysis but it still need further study by analysis the other exon of p53 gene and other oncogenes that involved in head and neck carcinoma.

\section{REFERENCES}

1. Syafriadi M, Ida-Yanemochi H, Ikarashi T, Maruyama S, Jen KY, Cheng J, Hoshina H, Takagi R, Saku T. Carcinoma in-situ of the oral mucosa has a definite tendency towards keratinization. Oral Med Pathol 2003; 8:43-44.

2. Coltrera MD, Zarbo RJ, Sakr WA, Gown AM. Markers for dysplasia of the upper autodigestive tract. Suprabasal expression of PCNA, p53 and CK 19 in alcohol-fixed, embedded tissue. Am J Pathol 1992; 41:817-25.

3. Sakr WA, Crissman JD, Gnepp DR. Squamous intraepithelial neoplasia the upper aero digestive tract. In Diagnostic Surgical Pathology of the Head and Neck. WB Saunders Company; 2001. p. 1-9.

4. World Health Organization International Histological Classification of tumors: Histological typing of cancer and precancer of the oral mucosa. $2^{\text {nd }}$ ed. Springer, 1997; p. 26.

5. The Japanese Society for Oral Pathology. Guidelines for histopathological diagnosis of borderline malignancies of the oral mucosa: A Preliminary Proposal, 2005; 7-11.

6. Syafriadi $\mathrm{M}$ and Takashi S. Histological types of oral carcinoma in-situ. Indonesian Journal of Dentistry 2006; 13(1):12-5.

7. Pindborg JJ, Reichart PA, Smith CJ, van der wall I. Histological typing of cancer and precancer of the oral mucosa, $2^{\text {nd }}$ ed. World Health Organization International Histological Classification of the Tumors, Springer-Verlag, Berlin, 2005.

8. Glazko GV, Koonin EV, Rogozin IB. Mutation hotspots in the p53 gene in tumors of different origin: correlation with evolutionary conservation and signs of positive selevtion. Biochimica et Biophysica Acta 2004; 1679:95-106.

9. Shahnavaz SA, Regezi JA, Bradley G, Dube ID, Jordan RCK. p53 gene mutation in sequential oral epithelial dysplasias and squamous cell carcinomas. J Pathol 2000; 190:417-22. 
10. Pindzola JA, Palazzo JP, Kovatich AJ, Tuma B, Nobel M. Expression of p21 ${ }^{\mathrm{WAF} 1 / \mathrm{CIP} 1}$ in soft tissue sarcomas: a comparative immunohistochemical study with p53 and Ki-67. Pathol Res Pract. 1998; 194:685-91.

11. Ogden GR, Kiddie RA, Lunny DP, Lane DP. Assessment of p53 protein expression in normal, benign, and malignant oral mucosa. J Pathol 1992; 166:389-94.

12. Regezie JA, Zarbo RJ, Regev E, Pisanty S, Silverman S, Gazit D. p53 expression in sequential oral dysplasias and in situ carcinomas. J Oral Pathol Med 1995; 24: 18-22.

13. Kushner J, Bradley G, Jordan RCK. Patterns of p53 and Ki-67 protein expression in epithelial dysplasia from the floor of the mouth. J Pathol 1997; 183:418-23.

14. Alves FA, Pires FR, de Almeida OP, Lopes MA, Kowalski LP. PCNA, Ki-67 and p53 expressions in submandibular salivary gland tumours. Int J Oral Maxillofac Surg 2004; 33:593-97.

15. Kovesi G, Szende B. Changes in apoptosis and mitotic index, p53 and $\mathrm{Ki}-67$ expression in various types of oral leukoplakia. Oncology 2003; 65:331-6.

16. Farrar M, Sandison A, Peston D, Gailani M. Immunocytochemical analysis of AE1/AE3, CK 14, Ki-67 and p53 expression in benign, premalignant and malignant oral tissue to establish putative markers of oral carcinoma. Br J Biomed Sci 2004; 61:117-24.
17. Cruz IB, Snijder PJF, Meijer CJ, Braakhuis BJ, Snow GB, Walboomers JM, Van Der Waal I. p53 expression above the basal cell layer in oral mucosa is an early event of malignant transformation and has predictive value for developing oral squamous cell carcinoma. J Pathol 1998; 184:360-68.

18. Mallofre C, Castillo M, Morente V, Sole M. Immunohistochemical expression of CK20, p53, and Ki-67 as a objective markers of uroepithelial dysplasia. Mod Pathol 2003; 16:187-91.

19. Taylor D, Koch WM, Zahurak M, Shah K, Sidransky D, Westra WH. Immunohistochemical detection of $\mathrm{p} 53$ protein accumulation in head and neck cancer: correlation with p53 gene alteration. Hum Pathol 1999; 30:1221-5.

20. Cruz I, Snijders PJ, Van Houten V, Vosjan M, Van der Waal I, Meijer CJ. Specific p53 immunostaining patterns are associated with smoking habits in patients with oral squamous cell carcinomas. J Clin Pathol 2002; 55:834-40.

21. Chiang CP, Huang JS, Wang JT, Liu BY, Kuo YS, Hahn LJ, Kuo MY. Expression of p53 protein correlates with decreased survival in patients with areca quid chewing and smoking-associated oral squamous cells carcinomas in Taiwan. J Oral Pathol Med 1999; 28:72-6.

22. Blencowe BJ. Exonic splicing enhancer: mechanism of action, diversity and role in human genetic diseases. TIBS 2000 ; 25: 106-10. 